\title{
Exposure and Exercise Training in Hypoxic Conditions as a New Obesity Therapeutic Modality: A Mini Review
}

\author{
Hun-Young Park', Jisu Kim', Mi-Young Park', Nana Chung ${ }^{1}$, Hyejung Hwang ${ }^{1}$, Sang-Seok Nam ${ }^{1}$, Kiwon Lim ${ }^{1,2, *}$ \\ 'Physical Activity and Performance Institute (PAPI) and 'Laboratory of Exercise Nutrition, Department of Physical Education, Konkuk University, Seoul, Korea
}

Obesity is an important health problem caused by positive energy balance. Generally, low calorie dietary intake combined with regular exercise is the most common modality to lose bodily fat in obese people. Although this is the first modality of choice for obesity treatment, it needs to be applied to obese patients for at least 12 weeks or more and it does not provide consistent results because it is difficult to suppress increased appetite due to exercise. Recently, many researchers have been applying hypoxic conditions for the treatment of obesity, as many studies show that people residing in high altitudes have a lower percentage of body fat and fewer obesity-related illnesses than people living at sea level. Hypoxic therapy treatment, including hypoxic exposure or hypoxic exercise training, is recommended as a way to treat and prevent obesity by suppression of appetite, increasing basal metabolic rate and fat oxidation, and minimizing side effects. Hypoxic therapy inhibits energy intake and appetite-related hormones, and enhances various cardiovascular and metabolic function parameters. These observations indicate that hypoxic therapy is a new treatment modality for inducing fat reduction and promoting metabolic and cardiovascular health, which may be an important and necessary strategy for the treatment of obesity. As such, hypoxic therapy is now used as a general medical practice for obesity treatment in many developed countries. Therefore, hypoxic therapy could be a new, practical, and useful therapeutic modality for obesity and obesity-related comorbidities.

Key words: Obesity, Hypoxia, Appetite regulation, Body weight

\author{
Received March 26, 2018 \\ Reviewed May 8, 2018 \\ Accepted May 16, 2018 \\ *Corresponding author \\ Kiwon Lim \\ https://orcid.org/0000-0003-3222-1783 \\ Laboratory of Exercise Nutrition, \\ Department of Physical Education, \\ Konkuk University, 120 Neungdong-ro, \\ Gwangjin-gu, Seoul 05029, Korea \\ Tel: +82-2-450-3827 \\ Fax: +82-2-450-6027 \\ E-mail: exercise@konkuk.ac.kr
}

\section{INTRODUCTION}

Obesity is currently an important social and health problem. It is caused by a positive energy balance via greater dietary intake than energy consumption in resting, physical activity, and exercise. ${ }^{1,2}$ According to recent estimates from the World Health Organization, $39 \%$ of individuals aged 18 years or older ( $\geq 1.9$ billion adults) were overweight and 13\% (600 million adults) were obese in $2014 .{ }^{3}$ Obesity via excessive fat accumulation is caused by increased dietary energy intake compared to energy consumption such as basal metabolic rate, diet induced thermogenesis, non-exercise activity thermogenesis, and exercise. This excessive fat increase is claimed to be associated with other factors, such as obesity-induced environmental conditions, oxidative stress, inflammation, and genetic factors. ${ }^{4,5}$ Chronic inflammatory responses, which are common among obese people, induce a variety of obesity-related diseases and increase oxidative stress in adipose tissue. Also, obesity is recognized as one of the major causes of various chronic diseases or disorders such as cardiovascular disease, insulin resistance, hypercholesterolemia, type 2 diabetes mellitus, nonalcoholic fatty liv-

Copyright (C) 2018 Korean Society for the Study of Obesity

(c) This is an Open Access article distributed under the terms of the Creative Commons Attribution Non-Commercial License (http://creativecommons.org/licenses/by-nc/4.0/) which permits unrestricted non-commercial use, distribution, and reproduction in any medium, provided the original work is properly cited. 
er, and metabolic syndromes. ${ }^{6}$

The combination of low calorie dietary intake and exercise is the most common modality for losing body fat in obese people. This combined intervention is the first step used in obesity treatment; however, this method should be tested for at least 24 weeks or more, it does not inhibit increased appetite due to exercise, and the results are inconsistent with a relatively large number of positive and negative results. ${ }^{7,8}$ If no reduction in body weight or body fat mass is observed after more than 12 weeks of combined intervention via low calorie diet and exercise, prescribing a drug treatment (e.g., stimulators of thermogenesis, absorption/digestion blockers, and appetite suppressants) can be considered with some limitations and considerations. ${ }^{9-11}$ However, few drugs are available for obesity treatment, and their effect is limited with benefits fading when the drugs are stopped. Since drug treatments inherently have more risks, pharmacologic therapy should be used only in patients in whom the benefit justifies the risk. ${ }^{11}$ As a last resort, patients with morbid severe obesity associated with comorbidities and/or various surgeries (e.g., gastrectomy, gastric bypass surgery, and gastric banding surgery) may be available as therapeutic methods associated with clinically significant and relatively long-term sustained weight loss. ${ }^{7,12}$ However, pharmacotherapy and surgery for the treatment of obesity are not recommended except for cases of severe morbid obesity because of the various adverse health effects. $^{13,14}$

Nowadays, many researchers are widely applying hypoxic conditions for the treatment of obesity based on the results of studies that people residing in high altitude have a lower percentage of body fat and obesity-related illness than people living at sea level. ${ }^{2,15}$ Hypoxic therapy is a novel obesity treatment method that is used as a general medical practice in many developed countries. ${ }^{7} \mathrm{Hy}-$ poxic therapies such as hypoxic exposure or hypoxic exercise training have been recommended as way to treat and prevent obesity by appetite suppression and minimization of side effects. ${ }^{1,16}$ Also, the increased oxygen delivering capacity of the blood is positively correlated with basal metabolic rate, and the enhanced oxygen transporting ability to working muscle by natural high altitude or artificial hypoxic condition contributes to improvement of fat oxidation and the reduction of body fat. ${ }^{17-20}$ Several previous studies have investigated the therapeutic benefits of exposure or exercise in vari- ous altitude or hypoxic conditions in obese patients. ${ }^{1,7,16,18,21-25}$ Therefore, this review summarizes recent evidence suggesting that exposure or exercise training under hypoxic conditions might be a valuable and viable obesity therapeutic modality.

\section{HYPOXIC CONDITION AND APPETITE}

When lowlanders are exposed to a natural high-altitude environment, sustained reduction in appetite and reduced dietary intake occur. This phenomenon is called "altitude anorexia," and is considered to be a consequence of acute altitude sickness occurring at the early stage of exposure to a high-altitude environment. ${ }^{26-28}$ However, previous studies suggest that hypoxemia per se provokes appetite changes. ${ }^{29,30}$ While the underlying mechanism for the modulation of appetite changes by natural altitude or artificial hypoxic conditions is not clearly understood, the change of appetite regulating hormones induced by hypoxic conditions is attracting attention as a major factor for appetite change and reduced dietary intake. $^{21,31,32}$ Leptin, the most common representative hormone associated with energy expenditure and appetite, is a hormone predominantly made by adipose cells that help to regulate energy balance by inhibiting hunger and is probably associated with reduced appetite and food intake observed at natural altitude or artificial hypoxic conditions. ${ }^{16}$ To date, various hormone and adipocytokines seem to affect appetite, dietary intake, and satiety (Table 1). Changes in several hormones and adipokines associated with appetite such as glucagon-like peptide-1 (GLP-1) ${ }^{33,34}$, ghrelin ${ }^{29,30,35}$, leptin $33,36,37$, pancreatic polypeptide $(\mathrm{PP})^{38}$, and peptide YY $(\mathrm{PYY})^{30,33}$ were demonstrated to be associated with exposure or exercise in various altitudes or hypoxic conditions.

In this regard, Wasse et al. ${ }^{30}$ examined the effect of resting and exercising in hypoxia (simulated 4,000 $\mathrm{m} ; \mathrm{FiO}_{2}, 0.127$ ) on energy intake, appetite, and plasma concentrations of acylated ghrelin and PYY. They concluded that acute exposure to normobaric hypoxic conditions induced a decrease in energy intake that may be associated with a reduction in plasma acylated ghrelin levels, and exercise also reduced acylated ghrelin levels but did not seem to interfere with the reduction found in hypoxic conditions. Debevec et al. ${ }^{39}$ evaluated whether daily moderate intensity exercise with a hypoxic condition (simulated 4,000 m; $\mathrm{FiO}_{2}, 0.127$ ) for 10 days changed 
Table 1. Appetite-related hormones and adipocytokines that are estimated to be affected by hypoxic conditions

\begin{tabular}{|c|c|}
\hline $\begin{array}{l}\text { Hormone or } \\
\text { adipocytokine }\end{array}$ & Function \\
\hline GLP-1 ( $)$ & $\begin{array}{l}\text { GLP-1 is thought promote satiety through several mechanisms, including } \\
\text { slowing gastric emptying and enhancing insulin biosynthesis and } \\
\text { secretion. Also, it decreases blood sugar levels in a glucose-dependent } \\
\text { manner by enhancing the secretion of insulin. }\end{array}$ \\
\hline Ghrelin ( $\downarrow)$ & $\begin{array}{l}\text { The hunger hormone ghrelin is a peptide hormone produced by } \\
\text { ghrelinergic cells in the gastrointestinal tract that functions as a } \\
\text { neuropeptide in the central nervous system and plays an important } \\
\text { role in regulating the distribution and rate of use of energy. }\end{array}$ \\
\hline Leptin ( $\uparrow)$ & $\begin{array}{l}\text { The hormone of energy expenditure leptin is a hormone predominantly } \\
\text { made by adipose cells that helps to regulate energy balance by } \\
\text { inhibiting hunger. Leptin is opposed by the actions of the hormone } \\
\text { ghrelin and both hormones act on receptors in the arcuate nucleus } \\
\text { of the hypothalamus to regulate appetite to achieve energy } \\
\text { homeostasis. }\end{array}$ \\
\hline $\mathrm{PP}(\uparrow)$ & $\begin{array}{l}\text { PP is a polypeptide secreted by PP cells in the endocrine pancreas } \\
\text { predominantly in the head of the pancreas and it functions to self- } \\
\text { regulate pancreatic secretion activities (endocrine and exocrine); it } \\
\text { also has effects on hepatic glycogen levels and gastrointestinal } \\
\text { secretions. PP has been shown to be reduced in conditions associated } \\
\text { with increased food intake and elevated in anorexia nervosa. }\end{array}$ \\
\hline $\operatorname{PYY}(\uparrow)$ & $\begin{array}{l}\text { PYY inhibits gastric motility and increases water and electrolyte } \\
\text { absorption in the colon. It may also suppress pancreatic secretion } \\
\text { and has been shown to reduce appetite. PYY works by slowing } \\
\text { gastric emptying; hence, it increases efficiency of digestion and } \\
\text { nutrient absorption after a meal. }\end{array}$ \\
\hline
\end{tabular}

$\uparrow$, increased secretion response by hypoxic condition; $\downarrow$, decreased secretion response by hypoxic condition; GLP-1, glucagon-like peptide-1; PP, pancreatic polypeptide; PYY, peptide YY.

appetite-related hormone levels and enhanced metabolic health. Consequently, exercise training with exposure to hypoxic conditions significantly changed appetite, appetite-related hormones, and augmented metabolic outcomes. However, they reported that gut permeability and glucose uptake were unchanged via exposure to hypoxic conditions regardless of exercise. Bailey et al. ${ }^{29}$ examined the influence of continuous and interval exercise while exposed to a hypoxic condition (simulated 2,980 $\mathrm{m} ; \mathrm{FiO}_{2}, 0.145$ ) for a short time (2.6 hours) on plasma concentrations of GLP-1, PYY, acylated ghrelin, and appetite in healthy normal weight men and they demonstrated that exposure to the hypoxic condition for a relatively short time can induce a decrease in plasma acylated ghrelin concentration and appetite. In addition, the response to appetite by exercise did not appear regardless of exercise modality. Mekjavic et al. ${ }^{33}$ assessed the effect of normobaric hypoxia (simulated 2,800 to $3,400 \mathrm{~m}$ ) on metabolism, gut hormones, and body composition in aerobic trained men and they reported that the hypoxic condition was likely correlated with increased noradrenaline fasting, fasting leptin, and reduced energy intake, especially hypoxic exposure without exercise training resulting in a reduced energy intake and a negative energy balance. Debevec et al. ${ }^{31}$ evaluated the effect of independent hypoxic exposure and combined hypoxic exposure and bed rest induced inactivity for 16 days on appetite modulation-related parameters in healthy males, and they reported that exposure to simulated $\geq 4,000 \mathrm{~m}$ normobaric hypoxic condition and/or inactivity by bed rest did not induce remarkable changes on the subject report on appetite or ad libitum intake. Matu et al. ${ }^{40}$ investigated dietary energy intake, appetite, gut hormone, and substrate oxidation responses to breakfast ingestion and exercise at simulated moderate (simulated 2,150 m, 15.8\% $\mathrm{O}_{2}$ ) and severe (simulated 4,300 m, 11.7\% $\mathrm{O}_{2}$ ), altitudes compared with sea level. As a result, they reported that exercise during acute exposure to a simulated severe altitude inhibited appetite, acylated ghrelin concentration, and energy intake in comparison with sea level; however, exercise during exposure to simulated moderate altitude did not influence these variables compared with sea level. Most previous studies associated with changes of appetite and appetite-related hormone for exposure or exercise to hypoxic conditions were performed on healthy normal weight males.

In a study of obese subjects, Lippl et al. ${ }^{16}$ examined the effect of hypobaric hypoxic conditions on body weight at high altitude (at low altitude, day 1 ; at the end of a 1-week stay at 2,650-m-high altitude, day 7 and day 14; 4 weeks after returning to low altitude, day 42) and they reported that significant decrease of weight, calories per day, and significant increase of basal metabolic rate and leptin concentration was found on day 14 compared to day 1 . Based on these results, they concluded that obese subjects lose weight at high altitude with reduced dietary energy intake and a higher metabolic rate and plasma leptin levels rise in natural high-altitude environment despite reduced body weight.

In summary, although the mechanism of appetite suppression via hypoxic condition has not yet been elucidated, exposure and exercise training in the hypoxic condition seems to induce reduced appetite and energy intake via a decrease in ghrelin and increase in leptin, PYY, PP, and norepinephrine. However, these comprehensive summaries suggest that various results are obtained depending on specific exposure conditions within that hypoxic environment 


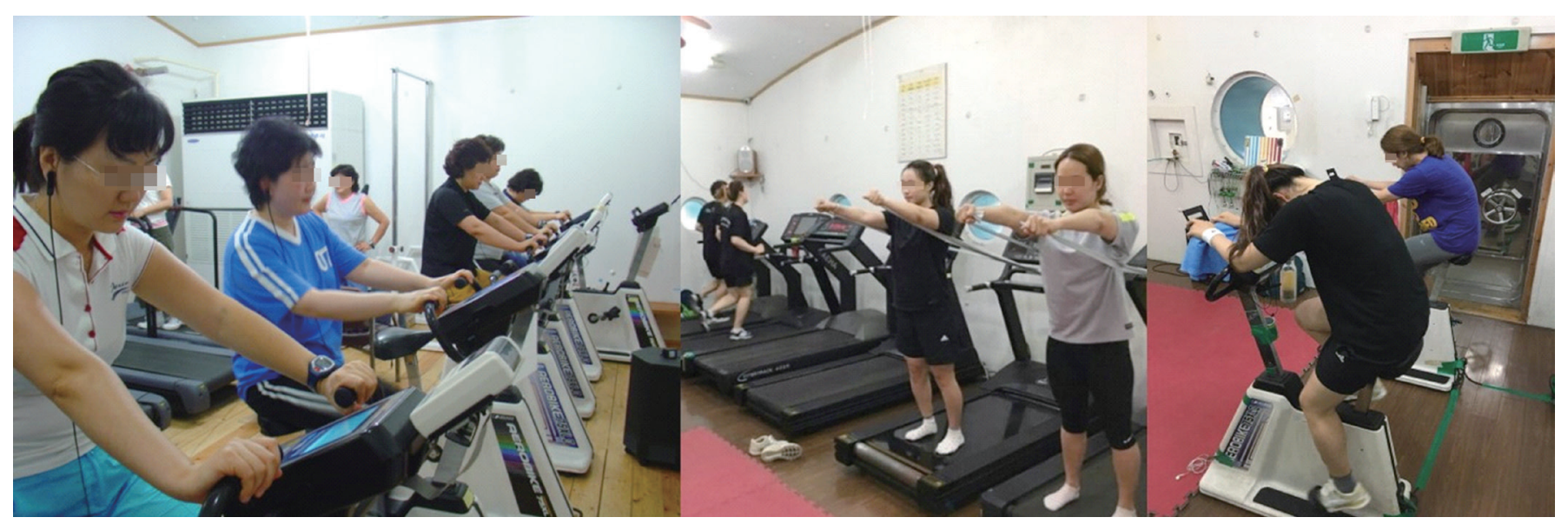

Figure 1. Practical application of hypoxic therapy for obese patients.

(e.g., the degree of hypoxic stimulation and exposure time, frequency, duration) or exercise training condition (e.g., exercise type, intensity, time, duration) to the hypoxic environment and difference according to characteristics. In addition, research on appetite suppression by hypoxic conditions in obese subjects is very limited and the physiological mechanisms are poorly understood overall. Therefore, there is a need for well-designed studies on appetite, energy intake, and appetite-related hormones by exposure and exercise training in hypoxic conditions.

\section{HYPOXIC THERAPY FOR OBESITY AND ITS APPLICATIONS}

Again, one of the new alternatives to address obesity is hypoxic therapy, which was recently used as a general medical modality and is well positioned in the field of alternative medicine. ${ }^{7}$ It is recommended that hypoxic therapy, such as hypoxic exposure or hypoxic exercise training, is a way to treat and prevent obesity (Fig. 1). Currently, we have identified that the inhibition of several appetite-related hormones by hypoxic conditions decreases appetite and dietary energy intake, causing the loss of body weight and percentage body fat. Furthermore, the use of hypoxic conditions can increase energy expenditure and basal metabolic rate by oxygen variation in organic systems. ${ }^{20,21,32}$ These findings suggest that hypoxic conditions can be used as a new modality to play a pivotal role in the treatment of obesity. In this section of the review, we focus on the therapeutic effects of hypoxic conditions and their potential applications.

\section{Therapeutic effects of hypoxic condition exposure on obesity}

The decrease in body weight and/or percentage body fat is thought to be caused by various factors; however, acute mountain sickness (AMS) is one representative cause of high altitude or hypoxic condition induced body weight loss via reduced appetite and its related reduced dietary energy intake. ${ }^{16}$ Obesity has been reported as one of the factors causing AMS and obese subjects are more susceptible to AMS and their frequent comorbidity, the prevalence of AMS in obese subjects, is reported to be three times higher than that in people with normal body mass index (BMI). ${ }^{21}$ Also, obese people have a higher frequency of pulmonary hypertension than normal body weight subjects. ${ }^{41}$ Hence, the hypoxic condition appears to be a double-edged sword with both positive and negative aspects. Hypoxic therapy applied using appropriate methods is considered to be a potential therapeutic modality in the treatment of metabolic and cardiovascular diseases caused by obesity. Urdampilleta et al. ${ }^{7}$ and Verges et al. ${ }^{42}$ summarized the compensatory mechanisms and responses to hypoxic conditions as shown in Table 2.

In general, hypoxic exposure, one of the modalities of hypoxic therapy, is a passive exposure to the hypoxic condition lasting from a few minutes to hours that is repeated daily over several days. ${ }^{7,21}$ Hypoxic exposure modality is mainly used by various intermittent hypoxic exposure (IHE) methods, which are interspersed with exposure to normoxic conditions or moderate hypoxic condition levels. Intermittent exposure to hypoxic conditions for 1 week is practically beneficial in weight loss. ${ }^{16,43}$ The exposure to actual high alti- 
Table 2. Mechanism of compensation for exposure to hypoxic conditions by Urdampilleta et al. ${ }^{7}$ and Verges et al. ${ }^{42}$

\begin{tabular}{|c|c|}
\hline Physiological response & Compensatory mechanism \\
\hline $\begin{array}{l}\text { Body weight-related } \\
\text { response }\end{array}$ & $\begin{array}{l}\text { Decreased resting leptin levels } \\
\text { Increased adrenergic system } \\
\text { Resting noradrenaline remains high posttreatment } \\
\text { Increased blood serotonin levels } \\
\text { Appetite is suppressed. }\end{array}$ \\
\hline $\begin{array}{l}\text { Cellular and metabolic } \\
\text { response }\end{array}$ & $\begin{array}{l}\text { Increased HIF-1 and VEGF expression } \\
\text { Angiogenesis } \\
\text { Increased glycolytic enzymes and number of mitochondria } \\
\text { Improved insulin sensitivity } \\
\text { Increases GLUT-4 }\end{array}$ \\
\hline $\begin{array}{l}\text { Cardiovascular } \\
\text { response }\end{array}$ & $\begin{array}{l}\text { Increases resting and maximal heart rate } \\
\text { Increases peripheral vasodilation } \\
\text { Increases diameter of arterioles } \\
\text { Increases } \mathrm{Hg}-\mathrm{O}_{2} \text { affinity } \\
\text { Normalizes blood pressure } \\
\text { Cardiovascular protection }\end{array}$ \\
\hline Respiratory response & $\begin{array}{l}\text { Hyperventilation } \\
\text { Increases lung diffusion capacity for } \mathrm{CO} \text { and } \mathrm{O}_{2} \\
\text { Increases the } \mathrm{CO}_{2} \text { reserve in sleeping } \\
\text { Decrease in } \mathrm{SaO}_{2} \text { was smaller. } \\
\text { Ventilation response during exercise increased. } \\
\text { Improves respiratory function }\end{array}$ \\
\hline
\end{tabular}

HIF-1, hypoxic inducible factor-1; VEGF, vascular endothelial growth factor; GLUT-4, glucose transporter-4; $\mathrm{Hg}$, hemoglobin; $\mathrm{O}_{2}$, oxygen; $\mathrm{CO}$, carbon monoxide; $\mathrm{CO}_{2}$, carbon dioxide production; $\mathrm{SaO}_{2}$, arterial $\mathrm{O}_{2}$ saturation.

tude and artificial hypoxic condition probably influences the loss of body weight via several appetite-related gut hormones and adipocytokines, energy substrate utilizing change, higher energy metabolic rate, reduced perception of hunger feeling together with reduced dietary food intake and various endocrine factors. ${ }^{16}$ Also, exposure to hypoxic conditions has been reported to be associated with greater weight loss in subjects with a higher BMI. ${ }^{43}$ Hypoxic inducible factor-1 expression changes by hypoxic condition changes helps to regulate mitochondrial function. ${ }^{44}$ Therefore, it is considered that the hypoxic exposure modality is a useful therapeutic method for obese subjects.

Until now, few studies have investigated the therapeutic effects of hypoxic condition exposure on obese subjects. In diet-induced obese mice models, Ling et al. ${ }^{45}$ reported that hypoxic exposure of the IHE method was shown that it compared with normoxic conditions in that IHE reduces body weight by enhancing liver leptin expression and increasing plasma leptin level, and the IHE method also increases plasma erythropoietin and insulin level and decreases plasma cholesterol and glucose level and thereby may effectively prevent obesity induced fatty liver disease. For healthy males, Brooks et al. ${ }^{46}$ reported that adaptation to the 4,000-m-high altitude by the IHE method was found to decrease blood glucose, induce higher glucose turnover, and result in enhanced insulin sensitivity at rest and during exercise. Mackenzie et al. ${ }^{47}$ concluded that acute exposure to hypoxic conditions can be attributed to enhanced short-term glycemic control via hypoxia-induced glucose tolerance improvement after 4 hours of hypoxic exposure that may be due to improved peripheral insulin sensitivity in patients with type 2 diabetes mellitus. Kelly et al. ${ }^{48}$ investigated the influence of acute hypoxia induced by natural high altitude on hormone and metabolism response to ingested glucose in young and healthy subjects and they concluded that acute exposure to high-altitude environments seems to increase glucose utilization as an energy source and results in a rapid metabolic response with associated hormonal changes. In a study of obese people, Lippl et al. ${ }^{16}$ reported a decrease in body weight and diastolic blood pressure and an increase in basal metabolic rate and leptin levels after 4 weeks of exposure to 2,650 $\mathrm{m}$ for 1 week in obese subjects, but there was no control group in this study. They concluded that the physiological mechanism for this is still unclear, but hypobaric hypoxic condition appears to play an important role.

In summary, there are very few studies focusing on the therapeutic effects of exposure to hypoxic conditions on obese subjects. The hypoxic exposure modality seems to be effective for obese subjects with reduced body weight via increased basal metabolic rate, insulin sensitivity, and leptin levels.

\section{Therapeutic effects of exercise training in hypoxic condition on obesity}

Combining hypoxia and exercise such as trekking at altitude or intermittent hypoxic training (IHT) using artificial equipment might be of therapeutic use for obese subjects. The IHT method, the living low and training high approach, commonly involves shorter hypoxic exposures such as approximately two to five sessions of $<3$ hours per week over a 4 to 12 week time period. ${ }^{1,8,18}$ Especially, the IHT method is one of the most effective nonpharmacologic therapies that activates the natural immune action of the 
body itself by repeatedly performing exercise training in an intermittent hypoxic environment and it is the most used hypoxic therapy for obesity treatment and health promotion. ${ }^{49}$ Although the hypoxic environment provides the subject with lower exercise load and hence lower mechanical stimuli, exercise training in hypoxic conditions may lead to change in body composition by decreased percentage of body fat and enhanced metabolic and cardiovascular function compared with normoxic training. Therefore, hypoxic training can be helpful in weight management programs for obesity subjects. ${ }^{21,23,25,50}$ Hypoxic training such as IHT is known to induce body weight loss via reduction of dietary energy intake as a consequence of a decrease in ghrelin and an increase of leptin or cholecystokinin, two satiety signaling hormones. ${ }^{21,50-52}$ The effects of hypoxic training can lead to inconsistent results depending on hypoxic exposure state with exercise condition (type, intensity, duration, and time, etc.). Because hypoxic conditions play an important role in the pathogenesis and principles of obesity and its associated complications, the relevant evidence must be carefully assessed for the therapeutic use of hypoxic conditions for the treatment of obesity.

Previous studies related to the effect of hypoxic training as an obesity therapeutic modality have been reported since the 2000s. Netzer et al. ${ }^{22}$ examined the influence of low intensity exercise for 90 minutes at $60 \%$ of the maximal heart rate, 3 days a week for 8 weeks, in either ambient $15 \% \mathrm{O}_{2}$ or $21 \% \mathrm{O}_{2}$ in two groups of 10 subjects with a BMI $>27 \mathrm{~kg} / \mathrm{m}^{2}$. They concluded that 8 weeks of moderate exercise three times per weeks for 90 minutes in ambient $15 \% \mathrm{O}_{2}$ hypoxic conditions induced greater body weight loss $(-1.14$ vs. $-0.03 \mathrm{~kg})$ in obese subjects compared with normoxia. Similarly, Haufe et al. ${ }^{25}$ classified 20 healthy males as one of two groups that performed similar exercise training in ambient $15 \% \mathrm{O}_{2}$ and $21 \% \mathrm{O}_{2}$ environmental conditions and then all subjects performed exercise three times for 60 minutes over a 4-week time period with measured heart rate at $3 \mathrm{mmol} / \mathrm{L}$ lactate level at pretraining exercise testing. They reported a greater improvement in percent body fat, triglycerol, fasting insulin level, area under the curve for insulin level and homeostatic model assessment index during an oral glucose tolerance test, despite the absolute exercise load under the hypoxic condition was lower compared to that in normoxic conditions (hypoxia vs. normoxia, 1.4 vs. $1.7 \mathrm{~W} / \mathrm{kg}$ ). Wiesner et al. ${ }^{23}$ conducted a single-blind study to examine the hypothesis that exercise training in hypoxic conditions $\left(n=24 ; \mathrm{FiO}_{2}, 15 \%\right)$ would have a greater improvement in body weight loss and metabolic riskrelated parameters compared to exercise training in normoxic conditions $\left(\mathrm{n}=21 ; \mathrm{FiO}_{2}, 21 \%\right)$. As a result, they reported that exercise training in hypoxic conditions induces better improvement in the response of health-related fitness, body composition, and metabolic risk-related parameters despite lower absolute exercise load compared to normoxic conditions.

As with the above studies, exercise training in hypoxic conditions can reduce absolute exercise load and mechanical stress can be particularly beneficial for obese patients with orthopedic comorbidities. More recently, Kong et al. ${ }^{24}$ randomly assigned subjects to either a normobaric hypoxia group $\left(\mathrm{FiO}_{2}, 16.4 \%-14.5 \%\right)$ or normobaric training group $\left(\mathrm{FiO}_{2}, 21 \%\right)$ and all subjects experienced 16-hour normoxia and 6-hour hypoxia or 22-hour normoxic training weekly. Then, they investigated whether IHT at the normobaric hypoxic condition combined with low-caloric diet had an additive effect on weight loss compared with normoxic training in obese young adults. As a result, IHT with low caloric diet had an additive improvement on body weight loss compared to normoxic training ( $-6.9 \mathrm{~kg}$ or $-7.0 \%$ vs. $-4.3 \mathrm{~kg}$ or $-4.2 \%)$. Park and $\mathrm{Lim}^{1}$ determined the effectiveness of aerobic exercise under hypoxic conditions for 6 weeks on body composition, blood pressure, arterial stiffness, and blood lipid level in 30- to 60-year-old women. For this, obese women above $30 \mathrm{~kg} / \mathrm{m}^{2}$ in BMI and percentage body fat volunteered to participate in the study as participants and were divided into three groups including a normoxic training group, $16.5 \% \mathrm{O}_{2}$ hypoxic training group, and $14.5 \% \mathrm{O}_{2}$ hypoxic training group. In the results, they demonstrated that the hypoxic training regime had a positive effect and good possibility for efficiency on body composition, blood pressure, arterial stiffness, and blood lipid level in middle aged obese women compared with normoxic training. Lee and $\mathrm{Kim}^{18}$, by applying the hypoxic training intervention period longer (total 12 weeks), investigated the effects of aerobic training in hypoxia on fat metabolism during resting and exercising and the body composition of people with obesity (body fat $\geq 25 \%$ for men and $\geq 30 \%$ women). They concluded that aerobic training in hypoxia reduces body fat and increases high-density lipoprotein cholesterol in obese subjects more greatly than training in normox- 
ia under the same exercise conditions.

To summarize, the complex treatment of excessive adiposity could be improved by prescribing low or moderate intensity exercise under moderate hypoxic conditions to obese subjects to reduce fat accumulation and avoid muscle depletion. In the future, various investigations should include whether the stay in moderate hypoxia alone without exercise increases weight loss compared to hypoxic training and if such a regimen would still be safe.

\section{CONCLUSION}

Exposure and exercise under hypoxic conditions in conjunction with decreased appetite, improved metabolism, enhanced utilization of fatty acids, and body weight loss are considered an interesting and important therapeutic modality for obesity treatment. Specifically, IHE and IHT, which are regiments that involve intermittent exposure or exercise in hypoxic conditions, have a very important clinical value in promoting general health and prevention. However, hypoxia appears to increase obesity-related health risk factors due to susceptibility to AMS and their frequent comorbidities. Hence, hypoxic conditions appear to be a double-edged sword with both positive and negative aspects. In other words, with optimal doses, hypoxic therapy might become a potential new obesity treatment strategy. Future investigation should verify whether exposure and exercise to hypoxic conditions could be a new therapeutic modality for obesity and obesity-related comorbidities and elucidate the underlying mechanisms and signaling pathways.

\section{CONFLICTS OF INTEREST}

The authors declare no conflict of interest.

\section{ACKNOWLEDGMENTS}

This study was supported by a grant from the National Research Foundation funded by the Korean Government (No. NRF-2015 M3C1B1019479). Also, the KU Research Professor Program of Konkuk University supported this paper.

\section{REFERENCES}

1. Park HY, Lim K. The effects of aerobic exercise at hypoxic condition during 6 weeks on body composition, blood pressure, arterial stiffness, and blood lipid level in obese women. Int J Sports Sci Med 2017;1:1-5.

2. Rhee EJ. Weight cycling and its cardiometabolic impact. J Obes Metab Syndr 2017;26:237-42.

3. Díaz-Gutiérrez J, Martínez-González MÁ, Pons Izquierdo JJ, González-Muniesa P, Martínez JA, Bes-Rastrollo M. Living at higher altitude and incidence of overweight/obesity: prospective analysis of the SUN cohort. PLoS One 2016;11:e0164483.

4. González-Muniesa P, Quintero P, De Andrés J, Martínez JA. Hypoxia: a consequence of obesity and also a tool to treat excessive weight loss. Sleep Breath 2015;19:7-8.

5. Querido JS, Sheel AW, Cheema R, Van Eeden S, Mulgrew AT, Ayas NT. Effects of 10 days of modest intermittent hypoxia on circulating measures of inflammation in healthy humans. Sleep Breath 2012;16:657-62.

6. Misra A, Khurana L. Obesity and the metabolic syndrome in developing countries. J Clin Endocrinol Metab 2008;93(11 Suppl 1):S9-30.

7. Urdampilleta A, González-Muniesa P, Portillo MP, Martínez JA. Usefulness of combining intermittent hypoxia and physical exercise in the treatment of obesity. J Physiol Biochem 2012; 68:289-304.

8. Wu T, Gao X, Chen M, van Dam RM. Long-term effectiveness of diet-plus-exercise interventions vs. diet-only interventions for weight loss: a meta-analysis. Obes Rev 2009;10:31323.

9. Elfhag K, Rössner S. Who succeeds in maintaining weight loss? A conceptual review of factors associated with weight loss maintenance and weight regain. Obes Rev 2005;6:67-85.

10. James WP, Astrup A, Finer N, Hilsted J, Kopelman P, Rössner $S$, et al. Effect of sibutramine on weight maintenance after weight loss: a randomised trial. Lancet 2000;356:2119-25.

11. Li Z, Maglione M, Tu W, Mojica W, Arterburn D, Shugarman LR, et al. Meta-analysis: pharmacologic treatment of obesity. Ann Intern Med 2005;142:532-46.

12. Maggard MA, Shugarman LR, Suttorp M, Maglione M, Sug- 
erman HJ, Livingston EH, et al. Meta-analysis: surgical treatment of obesity. Ann Intern Med 2005;142:547-59.

13. Tiwari MM, Goede MR, Reynoso JF, Tsang AW, Oleynikov $\mathrm{D}, \mathrm{McBride} \mathrm{CL}$. Differences in outcomes of laparoscopic gastric bypass. Surg Obes Relat Dis 2011;7:277-82.

14. Trayhurn P, Wang B, Wood IS. Hypoxia in adipose tissue: a basis for the dysregulation of tissue function in obesity? $\mathrm{Br} \mathrm{J}$ Nutr 2008;100:227-35.

15. Netzer N, Strohl K, Faulhaber M, Gatterer H, Burtscher M. Hypoxia-related altitude illnesses. J Travel Med 2013;20:24755.

16. Lippl FJ, Neubauer S, Schipfer S, Lichter N, Tufman A, Otto $\mathrm{B}$, et al. Hypobaric hypoxia causes body weight reduction in obese subjects. Obesity (Silver Spring) 2010;18:675-81.

17. Hamad N, Travis SP. Weight loss at high altitude: pathophysiology and practical implications. Eur J Gastroenterol Hepatol 2006; 18:5-10.

18. Lee JH, Kim CK. Effects of 12 weeks aerobic training in hypoxia on body composition and fat metabolism in obese adults. Int J Sports Sci Med 2017;1:10-6.

19. Tschöp M, Morrison KM. Weight loss at high altitude. Adv Exp Med Biol 2001;502:237-47.

20. Workman C, Basset FA. Post-metabolic response to passive normobaric hypoxic exposure in sedendary overweight males: a pilot study. Nutr Metab (Lond) 2012;9:103.

21. Kayser B, Verges S. Hypoxia, energy balance and obesity: from pathophysiological mechanisms to new treatment strategies. Obes Rev 2013;14:579-92.

22. Netzer NC, Chytra R, Küpper T. Low intense physical exercise in normobaric hypoxia leads to more weight loss in obese people than low intense physical exercise in normobaric sham hypoxia. Sleep Breath 2008;12:129-34.

23. Wiesner S, Haufe S, Engeli S, Mutschler H, Haas U, Luft FC, et al. Influences of normobaric hypoxia training on physical fitness and metabolic risk markers in overweight to obese subjects. Obesity (Silver Spring) 2010;18:116-20.

24. Kong Z, Zang Y, Hu Y. Normobaric hypoxia training causes more weight loss than normoxia training after a 4-week residential camp for obese young adults. Sleep Breath 2014;18: $591-7$.
25. Haufe S, Wiesner S, Engeli S, Luft FC, Jordan J. Influences of normobaric hypoxia training on metabolic risk markers in human subjects. Med Sci Sports Exerc 2008;40:1939-44.

26. Benso A, Broglio F, Aimaretti G, Lucatello B, Lanfranco F, Ghigo E, et al. Endocrine and metabolic responses to extreme altitude and physical exercise in climbers. Eur J Endocrinol 2007;157:733-40.

27. Kalson NS, Hext F, Davies AJ, Chan CW, Wright AD, Imray $\mathrm{CH}$, et al. Do changes in gastro-intestinal blood flow explain high-altitude anorexia? Eur J Clin Invest 2010;40:735-41.

28. Hackett PH, Roach RC. High-altitude illness. N Engl J Med 2001;345:107-14.

29. Bailey DP, Smith LR, Chrismas BC, Taylor L, Stensel DJ, Deighton K, et al. Appetite and gut hormone responses to moderate-intensity continuous exercise versus high-intensity interval exercise, in normoxic and hypoxic conditions. Appetite 2015;89:237-45.

30. Wasse LK, Sunderland C, King JA, Batterham RL, Stensel DJ. Influence of rest and exercise at a simulated altitude of 4,000 $\mathrm{m}$ on appetite, energy intake, and plasma concentrations of acylated ghrelin and peptide YY. J Appl Physiol (1985) 2012; 112:552-9.

31. Debevec T, Simpson EJ, Mekjavic IB, Eiken O, Macdonald IA. Effects of prolonged hypoxia and bed rest on appetite and appetite-related hormones. Appetite 2016;107:28-37.

32. Quintero P, Milagro FI, Campión J, Martínez JA. Impact of oxygen availability on body weight management. Med Hypotheses 2010;74:901-7.

33. Mekjavic IB, Amon M, Kölegård R, Kounalakis SN, Simpson L, Eiken $\mathrm{O}$, et al. The effect of normobaric hypoxic confinement on metabolism, gut hormones, and body composition. Front Physiol 2016;7:202.

34. Snyder EM, Carr RD, Deacon CF, Johnson BD. Overnight hypoxic exposure and glucagon-like peptide-1 and leptin levels in humans. Appl Physiol Nutr Metab 2008;33:929-35.

35. Morishima T, Goto K. Ghrelin, GLP-1, and leptin responses during exposure to moderate hypoxia. Appl Physiol Nutr Metab 2016;41:375-81.

36. Guerre-Millo M, Grosfeld A, Issad T. Leptin is a hypoxia-inducible gene. Obes Res 2002;10:856. 
37. Sierra-Johnson J, Romero-Corral A, Somers VK, Johnson BD. Last word on viewpoint: effect of altitude on leptin levels, does it go up or down? J Appl Physiol (1985) 2008;105:1691.

38. Riepl RL, Fischer R, Hautmann H, Hartmann G, Müller TD, Tschöp M, et al. Influence of acute exposure to high altitude on basal and postprandial plasma levels of gastroenteropancreatic peptides. PLoS One 2012;7:e44445.

39. Debevec T, Simpson EJ, Macdonald IA, Eiken O, Mekjavic IB. Exercise training during normobaric hypoxic confinement does not alter hormonal appetite regulation. PLoS One 2014; 9:e98874.

40. Matu J, Deighton K, Ispoglou T, Duckworth L. The effect of moderate versus severe simulated altitude on appetite, gut hormones, energy intake and substrate oxidation in men. Appetite 2017;113:284-92.

41. Wu TY, Ding SQ Liu JL, Yu MT, Jia JH, Chai ZC, et al. Who should not go high: chronic disease and work at altitude during construction of the Qinghai-Tibet railroad. High Alt Med Biol 2007;8:88-107.

42. Verges S, Chacaroun S, Godin-Ribuot D, Baillieul S. Hypoxic conditioning as a new therapeutic modality. Front Pediatr 2015; 3:58.

43. Boyer SJ, Blume FD. Weight loss and changes in body composition at high altitude. J Appl Physiol Respir Environ Exerc Physiol 1984;57:1580-5.

44. Solaini G, Baracca A, Lenaz G, Sgarbi G. Hypoxia and mitochondrial oxidative metabolism. Biochim Biophys Acta 2010; 1797:1171-7.

45. Ling Q, Sailan W, Ran J, Zhi S, Cen L, Yang X, et al. The ef- fect of intermittent hypoxia on bodyweight, serum glucose and cholesterol in obesity mice. Pak J Biol Sci 2008;11:86975.

46. Brooks GA, Butterfield GE, Wolfe RR, Groves BM, Mazzeo RS, Sutton JR, et al. Increased dependence on blood glucose after acclimatization to 4,300 m. J Appl Physiol (1985) 1991; 70:919-27.

47. Mackenzie R, Maxwell N, Castle P, Brickley G, Watt P. Acute hypoxia and exercise improve insulin sensitivity $\left(\mathrm{S}(\mathrm{I})\left(2^{*}\right)\right)$ in individuals with type 2 diabetes. Diabetes Metab Res Rev 2011; 27:94-101.

48. Kelly KR, Williamson DL, Fealy CE, Kriz DA, Krishnan RK, Huang $\mathrm{H}$, et al. Acute altitude-induced hypoxia suppresses plasma glucose and leptin in healthy humans. Metabolism 2010; 59:200-5.

49. Serebrovskaya TV, Xi L. Intermittent hypoxia training as nonpharmacologic therapy for cardiovascular diseases: practical analysis on methods and equipment. Exp Biol Med (Maywood) 2016;241:1708-23.

50. Millet GP, Debevec T, Brocherie F, Malatesta D, Girard O. Therapeutic use of exercising in hypoxia: promises and limitations. Front Physiol 2016;7:224.

51. Neubauer JA. Invited review: physiological and pathophysiological responses to intermittent hypoxia. J Appl Physiol (1985) 2001;90:1593-9.

52. Yingzhong Y, Droma Y, Rili G, Kubo K. Regulation of body weight by leptin, with special reference to hypoxia-induced regulation. Intern Med 2006;45:941-6. 